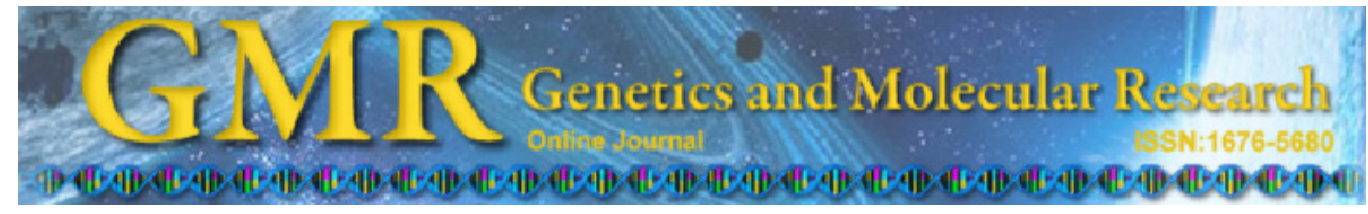

\title{
Proteins differentially expressed by Shiga toxin-producing Escherichia coli strain M03 due to the biliar salt sodium deoxycholate
}

\author{
C.B.A. Ribeiro ${ }^{1}$, M.G. Sobral' ${ }^{1}$, C.L. Tanaka ${ }^{1}$, C.B. Dallagassa ${ }^{1}$, G. Picheth ${ }^{1}$, \\ F.G.M. Rego ${ }^{1}$, D. Alberton ${ }^{1}$, L.F. Huergo ${ }^{2}$, F.O. Pedrosa ${ }^{2}$, E.M. Souza ${ }^{2}$ and \\ C.M.T. Fadel-Picheth ${ }^{1}$ \\ ${ }^{1}$ Departamento de Análises Clínicas, Universidade Federal do Paraná, \\ Curitiba, PR, Brasil \\ ${ }^{2}$ Departamento de Bioquímica e Biologia Molecular, \\ Universidade Federal do Paraná, Curitiba, PR, Brasil \\ Corresponding author: C.M.T. Fadel-Picheth \\ E-mail: fpicheth@ufpr.br
}

Genet. Mol. Res. 12 (4): 4909-4917 (2013)

Received October 3, 2012

Accepted September 9, 2013

Published October 24, 2013

DOI http://dx.doi.org/10.4238/2013.October.24.1

\begin{abstract}
Shiga toxin-producing Escherichia coli (STEC) can cause conditions ranging from diarrhea to potentially fatal hemolytic uremic syndrome. Enteropathogen adaptation to the intestinal environment is necessary for the development of infection, and response to bile is an essential characteristic. We evaluated the response of STEC strain M03 to the bile salt sodium deoxycholate through proteomic analysis. Cell extracts of strain M03 grown with and without sodium deoxycholate were analyzed by two-dimensional electrophoresis; the differentially expressed proteins were identified using matrix-assisted laser desorption/ionization time-of-flight mass spectrometry. Three proteins were found to be differentially expressed due to sodium deoxycholate. Glycerol dehydrogenase and phosphate acetyltransferase, which are involved in carbon metabolism and have been associated with virulence in some bacteria, were downregulated. The elongation factor Tu (TufA)
\end{abstract}


was upregulated. This protein participates in the translation process and also has chaperone activities. These findings help us understand strategies for bacterial survival under these conditions.

Key words: STEC; Proteomic analysis; Phosphate acetyltransferase; Sodium deoxycholate; Glycerol dehydrogenase; Elongation factor Tu

\section{INTRODUCTION}

Shiga toxin-producing Escherichia coli (STEC) are characterized by the ability to produce Stx1 and/or Stx2 toxins as their main virulence factor. These toxins belong to the Shiga-toxin (Stx) family, and act by inhibiting protein synthesis in eukaryotic cells leading to necrosis and cell death. STEC are an important cause of outbreaks and sporadic cases of bloody diarrhea (hemorrhagic colitis), non-bloody diarrhea and hemolytic uremic syndrome worldwide. STEC belonging to serotype O157:H7 are most important in North America, Japan and part of Europe, whereas other STEC serotypes can also cause disease and are more prominent in other countries (Kaper et al., 2004; Croxen and Finlay, 2010).

The infection strategy of pathogenic bacteria aims to efficiently proliferate in the infected host and to spread into new hosts. To achieve this goal, pathogens are equipped with basic sets of pathogenicity and fitness, including metabolic factors that allow optimal adaptation to the cellular, immunological, and metabolic characteristics of the infected niches. The genes encoding virulence factors enable the pathogens to occupy specific habitats in the host and to survive in these often hostile environments. The metabolic genes enable the pathogens to utilize nutrients provided by the colonized niche (Fuchs et al., 2012). For intestinal pathogens such as STEC, once ingested by a host they must successfully colonize the host intestinal mucosa to cause disease. These pathogenic strains of $E$. coli have acquired metabolic and virulence genes that enable them not only to compete successfully with the indigenous microbiota of the intestine but also to occupy new niches (Miranda et al., 2004; Fabich et al., 2008; Fuchs et al., 2012). To survive in the human gastrointestinal tract, microorganisms must respond to several environmental extreme conditions such as $\mathrm{pH}$ variations, low oxygen levels, nutrient limitation, elevated osmolarity and exposure to bile, all of which constitute potential impediments to survival. Bile is a digestive secretion that plays a major role in the emulsification and solubilization of lipids. It is also a bactericidal agent that has the ability to affect the phospholipids and proteins of cell membranes and disrupt cellular homeostasis (Begley et al., 2005). Bile is composed of a multitude of components, including proteins, ions, pigments, cholesterol and various bile salts. Of these components, bile salts have been shown to provide protection against pathogenic bacteria. Therefore, the ability of pathogens to tolerate bile is important for their survival and colonization of the intestine. It is becoming increasingly obvious that bile is used by enteric pathogens as an environmental signal to establish location and can influence the regulation of virulence genes. It is likely that some of the gene products involved in bile tolerance contribute to survival and colonization of the intestinal tract and thus function as virulence factors (Begley et al., 2005).

Proteomic analysis has become increasingly important, allowing global analysis of protein expression patterns and providing a better understanding of physiological changes related to various genetic and/or environmental conditions (Li et al., 2004; Sanchez et al., 2005; Weber et al., 2006; Xia et al., 2008). 
In this study, we analyzed the cellular proteome of STEC M03 grown in the presence and absence of the bile salt sodium deoxycholate (DOC) and identified the proteins differentially expressed in its presence.

\section{MATERIAL AND METHODS}

\section{Bacterial strain}

STEC strain M03 was originally isolated at Paraná State, Brazil, from feces of a child with uncomplicated diarrhea. STEC M03 produces Shiga-toxin type 1 (Stx1) and belongs to serotype O69:H11 (De Toni et al., 2009).

\section{Preparation of cellular proteins}

STEC M03 was grown overnight at $35^{\circ} \mathrm{C}$ in Luria-Bertani broth (LB). Cells were collected by centrifugation at $4000 \mathrm{rpm}$, at $4^{\circ} \mathrm{C}$ for $5 \mathrm{~min}$, and resuspended to an $\mathrm{OD}_{600 \mathrm{~mm}}$ of 0.02 in $400 \mathrm{~mL}$ of the same medium supplemented or not with $2.5 \mathrm{mM} \mathrm{DOC}$. After three hours of incubation at $35^{\circ} \mathrm{C}$, under stationary conditions, the cells were harvested by centrifugation at $800 \mathrm{x} g$ at $4^{\circ} \mathrm{C}$ for $7 \mathrm{~min}$ and the pellet was washed three times with $30 \mathrm{~mL}$ of low-salt washing sample buffer $\left(3.0 \mathrm{mM} \mathrm{KCl}, 1.5 \mathrm{mM} \mathrm{KH}_{2} \mathrm{PO}_{4}, 68 \mathrm{mM} \mathrm{NaCl}, 9.0 \mathrm{mM} \mathrm{NaH}_{2} \mathrm{PO}_{4}\right)$ and once with $30 \mathrm{~mL}$ of resuspension buffer $(10 \mathrm{mM}$ Tris- $\mathrm{HCl}, \mathrm{pH} 8.0,1.5 \mathrm{mM} \mathrm{MgCl}, 10 \mathrm{mM} \mathrm{KCl}, 0.5 \mathrm{mM}$ DTT). The pellet was then resuspended in a lysis solution (7 M urea, $2 \mathrm{M}$ thiourea, $40 \mathrm{mM}$ DTT, 4\% CHAPS (w/v), 2\% Pharmalyte 3-10 (v/v), 1\% proteases inhibitor (v/v)), and lysed by 3 cycles of freeze/thawing. One microliter of the nuclease mix (GE Healthcare, Uppsala, Sweden) was added for each $100 \mu \mathrm{L}$ of lysis solution used, the mixture was then centrifuged at $10,000 \mathrm{~g}$ for $15 \mathrm{~min}$ at $4^{\circ} \mathrm{C}$. The supernatant was stored at $-20^{\circ} \mathrm{C}$ until use. Protein concentration was determined by the Bradford method using bovine serum albumin as standard. Four independent experiments were performed, each one in duplicate.

\section{2-D electrophoresis and data analysis}

Protein isoelectric focusing was performed with $13 \mathrm{~cm}$ IPG strips and linear $\mathrm{pH}$ in the range 4-7 in an Ettan IPGphor Isoelectric Focusing System (GE Healthcare). The strips were rehydrated with rehydration buffer ( $2 \mathrm{M}$ thiourea, $7 \mathrm{M}$ urea, $\%$ CHAPS, $0.05 \%$ DTT, $0.5 \%$ Pharmalyte $\mathrm{pH} 3-10$ and $0.002 \%$ bromophenol blue) containing $350 \mu \mathrm{g}$ cell extract protein in a final volume of $250 \mu \mathrm{L}$. Strips were rehydrated for $11 \mathrm{~h}$ at $20 \mathrm{~V}$, and then submitted to the isoelectric focusing using the following conditions: $500 \mathrm{Vh} ; 800 \mathrm{Vh} ; 11300 \mathrm{Vh}$ and $12000 \mathrm{Vh}$, for a total of $17.5 \mathrm{kV}$. After this step, the strips were sequentially treated for 15 min with equilibration buffer (75 mM Tris-HCl, pH 8.8, $6 \mathrm{M}$ urea, 29.3\% glycerol (v/v), 2\% SDS (w/v) and 0.002\% bromophenol blue) containing $1 \%$ DTT (w/v), and then in equilibration buffer supplemented with 3.5\% iodoacetamide $(\mathrm{w} / \mathrm{v})$. The second dimension was performed in SDS- polyacrylamide (12\%) gel electrophoresis in a Hoefer SE 600 vertical electrophoresis system (GE Healthcare) until the front reached the bottom of the gel, at $45 \mathrm{~mA} / \mathrm{gel}, 11^{\circ} \mathrm{C}$. The gels were stained overnight with PhastGel Blue R (GE Healthcare). Spot detection and quantification were performed with Image Master2D Platinum 5.0 (GE Healthcare) software. A protein was considered to be 
differentially expressed in the presence of DOC when the mean normalized spot volume varied at least 1.7- fold relative to the control (absence of DOC) and $\mathrm{P}<0.05$ (Student $t$-test).

\section{Protein digestion and mass spectrometry identification}

Spots of protein differentially expressed were excised manually from the 2D gels and destained twice in $400 \mu \mathrm{L} \mathrm{50 \%}$ acetonitrile and $25 \mathrm{mM}$ ammonium bicarbonate $\mathrm{pH} 8.0$, for 30 $\min$. The gel pieces were then immersed in $200 \mu \mathrm{L} 100 \%$ acetonitrile for $5 \mathrm{~min}$. The acetonitrile was removed and the gel dried at room temperature. Protein digestion was performed with $20 \mathrm{ng} /$ $\mu \mathrm{L}$ sequencing grade trypsin (Promega, Madison, WI, USA) in $10 \%$ acetonitrile and $40 \mathrm{mM}$ ammonium bicarbonate $\mathrm{pH} 8.0$, in a final volume of $10 \mu \mathrm{L}$ and incubated overnight at $37^{\circ} \mathrm{C}$ (Westermeier and Naven, 2002). Aliquots of $1 \mu \mathrm{L}$ of the digests were then mixed with a saturated solution of $\alpha$-cyano-4-hydroxycinnamic acid (in 50\% acetonitrile, $0.1 \%(\mathrm{v} / \mathrm{v})$ trifluoroacetic acid), spotted onto the MALDI target and allowed to dry. Mass spectra were acquired using a MALDI-TOFMS/MS Autoflex spectrometer (Bruker Daltonics, Bremen, Germany) in a positive ion reflection/ delayed extraction mode with an accelerating voltage of $20 \mathrm{kV}$, delay time of $150 \mathrm{~ns}$ and acquisition mass range 800-3200 Da. External calibration was performed using the peptide calibration standard II (Bruker Daltonics). Peak lists were created using Flex Analysis 3.0 (Bruker Daltonics). Search parameters allowed for one missed tryptic cleavage site. The carbamidomethylation of cysteine was set as fixed and oxidation of methionine as variable modification. Error tolerance was $100 \mathrm{ppm}$ for peptide mass fingerprint search, and for MS/MS ion search was 0.6 Da. MASCOT 2.2 (www.matrixscience.com) was used to identify proteins from peptide mass fingerprints, and the searches were performed against the Swiss-Prot database. Protein identifications were confirmed by analyzing the same spot from at least two different gels.

\section{RESULTS AND DISCUSSION}

Bile resistance is an essential characteristic of enteric bacteria that allows their survival in the intestinal environment (Begley et al., 2005; Merritt and Donaldson, 2009). Bile salts penetrate the E. coli outer membrane through OmpF porin (Thanassi et al., 1997), and are able to cause membrane perturbations, oxidative stress, and DNA damage (Bernstein et al., 1999; Begley et al., 2005; Merritt and Donaldson, 2009). It was found that in response to bile $E$. coli is able to actively pump out bile salts through the efflux system AcrAB, thus limiting the toxic action of these compounds (Thanassi et al., 1997). In the diarrheagenic strains of E. coli, enteropathogenic E. coli (EPEC) and atypical enteropathogenic E. coli (aEPEC) bile salt stress resulted in an increase in adhesion of bacteria to human epithelial cells (de Jesus et al., 2005; Torres et al., 2007). Microarray analysis of STEC 0157:H7 indicated that the presence of bile salts resulted in protective alterations of the outer membrane, downregulating the expression of OmpF porin, through which bile pass into the periplasm of E. coli, and upregulating the efflux pump AcrA-AcrB, thereby limiting the toxic effects on the bacteria. Other responses, which do not appear to be required for resistance to bile itself, were also observed. Among them, the upregulation of genes whose products are responsible for lipid A modification conferring bacterial resistance to several cationic antimicrobial peptides, suggesting that bile may be acting as an environmental signal which triggers outer membrane modifications for resistance to defensins, part of the innate immune system in the small intestine (Kus et al., 2011). 
It has been proposed that bile serves as an environmental signal that triggers the expression of adaptive responses, including expression of colonization and virulence genes in enteric bacteria permitting successful transit through the intestine (Prouty and Gunn, 2000; Begley et al., 2005; Merritt and Donaldson, 2009; Kus et al., 2011).

In the present work, the response of STEC M03 to the presence of the bile salt DOC was analyzed by $2 \mathrm{D}$ electrophoresis. Approximately 340 protein spots were detected in the $2 \mathrm{D}$ gels prepared with the cellular extracts of STEC M03 in both tested conditions (absence and presence of DOC); representative maps are shown in Figure 1. No protein exclusively expressed in the presence of DOC was detected. However, five proteins had their expression affected by DOC and three of them were identified, with two being downregulated (Table 1, Figure 1).

A

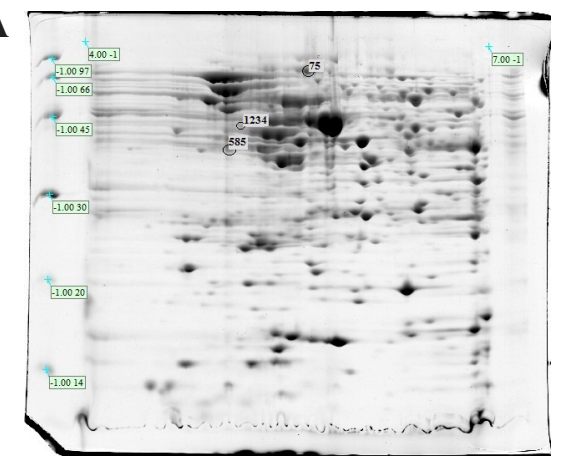

B

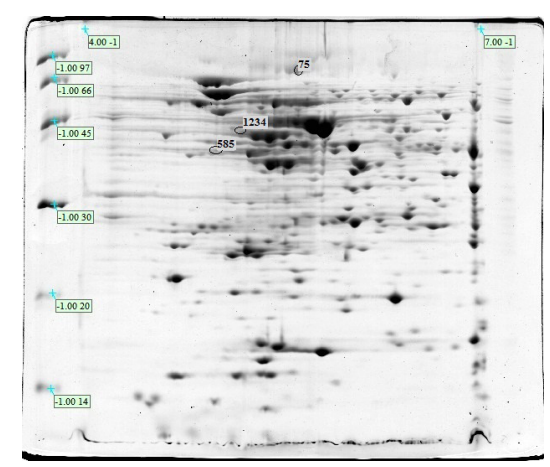

Figure 1. 2-D electrophoresis of protein cellular extract of STEC M03 grown in the presence (A) and absence (B) of $2.5 \mathrm{mM}$ sodium deoxycholate. Numbers in circles indicate the proteins differentially expressed in the presence of DOC.

\begin{tabular}{|c|c|c|c|c|c|c|c|c|c|c|c|}
\hline 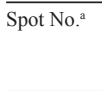 & Protein ID & $\begin{array}{l}\text { Accession } \\
\text { No. }^{b}\end{array}$ & $\begin{array}{l}\text { Strain with } \\
\text { greater score }\end{array}$ & $\begin{array}{c}\mathrm{MW} / \mathrm{pI} \\
\text { experimental } \\
(\mathrm{kDa})\end{array}$ & $\begin{array}{c}\mathrm{MW} / \mathrm{pI} \\
\text { theoretical } \\
(\mathrm{kDa})^{\mathrm{c}}\end{array}$ & $\begin{array}{l}\text { Peptide } \\
\text { search/ } \\
\text { match }^{d}\end{array}$ & $\begin{array}{c}\text { Sequence } \\
\text { coverage } \\
(\%)\end{array}$ & Score $^{e}$ & $\begin{array}{c}\text { Fold- } \\
\text { change }^{f}\end{array}$ & $\mathrm{MS}^{\mathrm{B}}$ & Fragmentation $^{h}$ \\
\hline \multicolumn{12}{|c|}{ Proteins downregulated in the presence of $2.5 \mathrm{mM}$ sodium deoxycholate } \\
\hline 585 & $\begin{array}{l}\text { Glycerol } \\
\text { dehydrogenase }\end{array}$ & gi 71159372 & E. coli $\mathrm{O} 6$ & $38 / 5.06$ & $39 / 4.81$ & - & 2 & 27 & 3.90 & MS2 & LGEYLKPLAER \\
\hline 75 & $\begin{array}{l}\text { Phosphate } \\
\text { acetyltransferase }\end{array}$ & gi 71152910 & E. coli K-12 & $73 / 5.65$ & $77 / 5.28$ & $25 / 10$ & 17 & 93 & 1.85 & MS/MS2 & $\begin{array}{l}\text { DAEVVLVEGLV } \\
\text { PTR }\end{array}$ \\
\hline \multicolumn{12}{|c|}{ Protein upregulated in the presence of $2.5 \mathrm{mM}$ sodium deoxycholate } \\
\hline 1234 & $\begin{array}{l}\text { Elongation } \\
\text { factor } \mathrm{Tu}\end{array}$ & gi 68053541 & $\begin{array}{l}\text { E. coli } \\
\text { O157:H7 }\end{array}$ & $43 / 5.16$ & $43 / 5.30$ & $28 / 11$ & 36 & 119 & 1.70 & MS & - \\
\hline
\end{tabular}

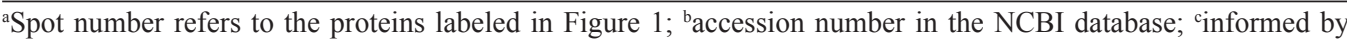
MASCOT/Swiss-Prot database; ${ }^{d}$ number of searched and matched peptides; ${ }^{\mathrm{e}}$ score obtained in matching by the MASCOT software; ${ }^{\mathrm{f}}$ change in abundance of protein spots compared to the control; ${ }^{\text {gindicate }}$ if the proteins were identified by MS or $\mathrm{MS}^{2}$ mode; heptide fragment identified by $\mathrm{MS}^{2}$ mode.

One of the proteins downregulated corresponds to glycerol dehydrogenase GldA (EC 1.1.1.6) which has broad substrate specificity (Tang et al., 1979; Kelley and Dekker, 1985; Subedi et al., 2008). In E. coli GldA expression in stationary phase is higher than during logarithmic phase of growth, and full expression is achieved in the presence of hydroxyacetone under 
stationary-phase growth (Truniger and Boos, 1994). However, the role of this enzyme is not clearly established (Tang et al., 1979; Truniger and Boos, 1994). On basis on the affinity and specificity of the enzyme towards dihydroxyacetone (DHA) at physiological $\mathrm{pH}$, and the sensitivity of a gldA mutant to this compound, it was recently proposed that the primary role of $E$. coli GldA is to regulate the intracellular level of dihydroxyacetone, a toxic metabolite, by converting it to glycerol (Subedi et al., 2008). However, a key role for GldA in fermentative glycerol dissimilation was recently described in E. coli. In this pathway, GldA is responsible for the conversion of glycerol to DHA, which is sequentially transformed by dihydroxyacetone kinase, to the glycolytic intermediate DHA-phosphate. Additionally, GldA is also involved in the synthesis of 1,2-propanediol from hydroxyacetone, providing a means of consuming excess reducing equivalents during cell growth, maintaining redox-balanced conditions (Gonzalez et al., 2008).

In addition to a role in metabolism, a function in virulence has also been suggested for proteins with glycerol dehydrogenase activity. In E. coli $\mathrm{K} 1$, a cause of neonatal meningitis, it was suggested that $\mathrm{CglD}$, a protein that shares high homology with GldA and has glycerol dehydrogenase activity, is involved in virulence, where it is associated with induction of the inflammatory response and severe damage to the host (Zhang et al., 2009).

In Salmonella enterica serovar Typhimurium, there are two putative glycerol dehydrogenase genes, gldA coding for GldA, and another called $g l h A$, coding for a glycerol dehydrogenase hypothetical or alternative GlhA. Glycerol dehydrogenase activity is required for full expression of hilA, a regulator of Salmonella pathogenicity island 1 (SPI-1), which is required for invasion of epithelial cells of the intestine. In gldA and glhA mutants, hilA expression is approximately 80 and $110 \%$, respectively, compared to the wild-type strain. For the double mutant, hilA expression was approximately $60 \%$ of that of the parent strain, suggesting that these two genes are redundant for activation of hilA and that either one is required for hilA full expression (Nakayama and Watanabe, 2006). Furthermore, in the presence of bile, there is a marked decrease in transcription of SPI-1 genes (Prouty and Gunn, 2000; Prouty et al., 2004; Hernandez et al., 2012), suggesting that Salmonella uses bile as an environmental signal to repress its invasive capacity in the intestine lumen where bile concentrations are high, but that after the penetration of the mucus layer and association with intestinal cells, when bile concentrations are decreased, invasion may then be initiated (Prouty and Gunn, 2000; Begley et al., 2005).

Although the physiological role of GldA is uncertain, this enzyme is associated with STEC M03 response to DOC. We speculate that in addition to a role in glycerol metabolism, GldA may also be associated with virulence in strain M03.

Phosphate acetyltransferase (Pta, EC 2.3.1.8), an enzyme involved in acetate dissimilation, was also found to be downregulated in STEC M03 in the presence of DOC. Acetate is produced from acetyl coenzyme A (CoA) in reactions catalyzed by Pta and acetate kinase (AckA). Pta reversibly converts acetyl-CoA and inorganic phosphate to acetyl-phosphate and regenerates $\mathrm{CoA}$, while AckA reversibly converts acetyl-phosphate and ADP to acetate and ATP, coupling energy metabolism with that of carbon and phosphorus. In E. coli, the levels of AckA and Pta, as well as their enzymatic activity, vary in response to diverse environmental factors such as anaerobic conditions (Wolfe, 2005). The downregulation of Pta in presence of DOC may be related to the role of acetyl CoA, a key intermediate in the degradation and biosynthesis of lipids. Considering that DOC may cause damage to the bacterial membrane (Begley et al., 2005), increased lipid synthesis that depends on acetyl CoA may be involved. Therefore, the downregulation of Pta, reducing the formation of acetyl phosphate, would increase the availability of acetyl CoA for lipid synthesis. 
The cell pellet obtained from STEC M03 cultures grown in presence of DOC was smaller than that from cultures in its absence (not shown). This effect may be related to the downregulation of Pta since acetyl-phosphate, which is generated in a reaction catalyzed by $\mathrm{Pta}$, regulates various cellular processes such as cell division, nitrogen assimilation and osmoregulation, besides flagellar biosynthesis and assembly, biofilm development, some stress effectors and expression of outer membrane porins (Shin and Park, 1995; Pruss, 1998; Wolfe et al., 2003; Wolfe, 2005). In addition, mutants for Pta or Pta and AckA grow more slowly than wild type E. coli (Pruss, 1998; Wolfe et al., 2003). Acetyl phosphate also regulates the biosynthesis of some virulence factors such as pili and capsule (Wolfe et al., 2003; Wolfe, 2005), and plays a role in the pathogenesis of some bacteria. A pta mutant of the urinary E. coli CFT073 showed the inability to colonize the mouse kidney (Anfora et al., 2008). In Salmonella enterica Typhimurium a pta mutant was shown to be impaired in growth and attenuated in BALB/c mice (Kim et al., 2006). In Vibrio cholerae, a pta mutant also had a growth defect, did not produce the toxin co-regulated pilus, and also had reduced production of the cholera toxin (Chiang and Mekalanos, 1998). It has been suggested that acetyl phosphate can serve as a global signal in bacterial pathogenesis (Xu et al., 2010).

Considering that both, GldA and Pta have been associated with virulence in bacteria, we speculate that these enzymes, in addition of their metabolic roles, may also participate in the virulence of STEC M03.

The elongation factor $\mathrm{Tu}$ (EF-Tu, TufA) was found to be up-regulated by DOC in strain M03 (Figure 1, Table 1). This protein is part of the translation machinery transporting the aminoacyl-tRNA to the ribosome. However, it has been shown that E. coli EF-Tu also has chaperonelike activities in addition to its function in translation. EF-Tu interacts with unfolded and denatured proteins and has been implicated in protein folding and renaturation when the bacteria are submitted to different stresses, including heat shock and guanidine, which denature protein, and the reducing agent dithiothreitol which disturbs the redox balance in the cytoplasm (Caldas et al., 1998; Han et al., 2008). EF-Tu is also overexpressed in Bifidobacterium longum NCIMB 8809 after bile salt exposure (Sanchez et al., 2005). Furthermore, it was shown that EF-Tu exhibits higher expression in E. coli cells isolated from the gastrointestinal tract than those isolated from feces cultures of gnotobiotic mice, suggesting that passage through the intestine activates its expression (Alpert et al., 2009). EF-Tu overexpression may be a protective response of strain M03 to overcome cellular damage after DOC exposure, by acting as a chaperone.

To cause infection, pathogenic bacteria must obtain the nutrients necessary for growth and survival from the infection site. Pathogenic bacteria respond to specific signals within host microenvironments, and their proliferation requires specific metabolic pathways, and thus, it is of fundamental importance to understand the bacterial physiology at the infection site (Brown et al., 2008) to aid the development of new therapeutic strategies. Our results indicate that the bile salt DOC affects the expression of at least three proteins in STEC M03. The downregulation of Pta and GldA may be related to metabolic and virulence control in STEC M03 under this study condition, while upregulation of EF-Tu is probably part of a general response to chemical stress. The specific roles of these proteins in resistance to bile and pathogenicity of STEC will be further investigated.

\section{ACKNOWLEDGMENTS}

Research supported by Fundação Araucária, the Brazilian Program of National 
Institutes of Science and Technology - INCT/ Brazilian Research Council - CNPq/MCT, CAPES-REUNI and PIBIC/CNPq.

\section{REFERENCES}

Alpert C, Scheel J, Engst W, Loh G, et al. (2009). Adaptation of protein expression by Escherichia coli in the gastrointestinal tract of gnotobiotic mice. Environ. Microbiol. 11: 751-761.

Anfora AT, Halladin DK, Haugen BJ and Welch RA (2008). Uropathogenic Escherichia coli CFT073 is adapted to acetatogenic growth but does not require acetate during murine urinary tract infection. Infect. Immun. 76: 5760-5767.

Begley M, Gahan CG and Hill C (2005). The interaction between bacteria and bile. FEMS Microbiol. Rev. 29: 625-651.

Bernstein C, Bernstein H, Payne CM, Beard SE, et al. (1999). Bile salt activation of stress response promoters in Escherichia coli. Curr. Microbiol. 39: 68-72.

Brown SA, Palmer KL and Whiteley M (2008). Revisiting the host as a growth medium. Nat. Rev. Microbiol. 6: 657-666.

Caldas TD, El Yaagoubi A and Richarme G (1998). Chaperone properties of bacterial elongation factor EF-Tu. J. Biol. Chem. 273: 11478-11482.

Chiang SL and Mekalanos JJ (1998). Use of signature-tagged transposon mutagenesis to identify Vibrio cholerae genes critical for colonization. Mol. Microbiol. 27: 797-805.

Croxen MA and Finlay BB (2010). Molecular mechanisms of Escherichia coli pathogenicity. Nat. Rev. Microbiol. 8: 26-38.

de Jesus MC, Urban AA, Marasigan ME and Barnett Foster DE (2005). Acid and bile-salt stress of enteropathogenic Escherichia coli enhances adhesion to epithelial cells and alters glycolipid receptor binding specificity. J. Infect. Dis. 192: 1430-1440.

De Toni F, de Souza EM, Pedrosa FO, Klassen G, et al. (2009). A prospective study on Shiga toxin-producing Escherichia coli in children with diarrhea in Parana State, Brazil. Lett. Appl. Microbiol. 48: 645-647.

Fabich AJ, Jones SA, Chowdhury FZ, Cernosek A, et al. (2008). Comparison of carbon nutrition for pathogenic and commensal Escherichia coli strains in the mouse intestine. Infect. Immun. 76: 1143-1152.

Fuchs TM, Eisenreich W, Heesemann J and Goebel W (2012). Metabolic adaptation of human pathogenic and related nonpathogenic bacteria to extra- and intracellular habitats. FEMS Microbiol. Rev. 36: 435-462.

Gonzalez R, Murarka A, Dharmadi Y and Yazdani SS (2008). A new model for the anaerobic fermentation of glycerol in enteric bacteria: trunk and auxiliary pathways in Escherichia coli. Metab. Eng. 10: 234-245.

Han KY, Park JS, Seo HS, Ahn KY, et al. (2008). Multiple stressor-induced proteome responses of Escherichia coli BL21(DE3). J. Proteome Res. 7: 1891-1903.

Hernandez SB, Cota I, Ducret A, Aussel L, et al. (2012). Adaptation and preadaptation of Salmonella enterica to Bile. PLoS Genet. 8: e1002459.

Kaper JB, Nataro JP and Mobley HL (2004). Pathogenic Escherichia coli. Nat. Rev. Microbiol. 2: 123-140.

Kelley JJ and Dekker EE (1985). Identity of Escherichia coli D-1-amino-2-propanol:NAD+ oxidoreductase with E. coli glycerol dehydrogenase but not with Neisseria gonorrhoeae 1,2-propanediol:NAD+ oxidoreductase. J. Bacteriol. 162: 170-175.

Kim YR, Brinsmade SR, Yang Z, Escalante-Semerena J, et al. (2006). Mutation of phosphotransacetylase but not isocitrate lyase reduces the virulence of Salmonella enterica serovar Typhimurium in mice. Infect. Immun. 74: 2498-2502.

Kus JV, Gebremedhin A, Dang V, Tran SL, et al. (2011). Bile salts induce resistance to polymyxin in enterohemorrhagic Escherichia coli O157:H7. J. Bacteriol. 193: 4509-4515.

Li M, Rosenshine I, Tung SL, Wang XH, et al. (2004). Comparative proteomic analysis of extracellular proteins of enterohemorrhagic and enteropathogenic Escherichia coli strains and their ihf and ler mutants. Appl. Environ. Microbiol. 70: 5274-5282.

Merritt ME and Donaldson JR (2009). Effect of bile salts on the DNA and membrane integrity of enteric bacteria. J. Med. Microbiol. 58: 1533-1541.

Miranda RL, Conway T, Leatham MP, Chang DE, et al. (2004). Glycolytic and gluconeogenic growth of Escherichia coli O157:H7 (EDL933) and E. coli K-12 (MG1655) in the mouse intestine. Infect. Immun. 72: 1666-1676.

Nakayama S and Watanabe H (2006). Mechanism of hilA repression by 1,2-propanediol consists of two distinct pathways, one dependent on and the other independent of catabolic production of propionate, in Salmonella enterica serovar Typhimurium. J. Bacteriol. 188: 3121-3125.

Prouty AM and Gunn JS (2000). Salmonella enterica serovar typhimurium invasion is repressed in the presence of bile. Infect. Immun. 68: 6763-6769.

Prouty AM, Brodsky IE, Manos J, Belas R, et al. (2004). Transcriptional regulation of Salmonella enterica serovar Typhimurium genes by bile. FEMS Immunol. Med. Microbiol. 41: 177-185.

Genetics and Molecular Research 12 (4): 4909-4917 (2013)

CFUNPEC-RP www.funpecrp.com.br 
Pruss BM (1998). Acetyl phosphate and the phosphorylation of OmpR are involved in the regulation of the cell division rate in Escherichia coli. Arch. Microbiol. 170: 141-146.

Sanchez B, Champomier-Verges MC, Anglade P, Baraige F, et al. (2005). Proteomic analysis of global changes in protein expression during bile salt exposure of Bifidobacterium longum NCIMB 8809. J. Bacteriol. 187: 5799-5808.

Shin S and Park C (1995). Modulation of flagellar expression in Escherichia coli by acetyl phosphate and the osmoregulator OmpR. J. Bacteriol. 177: 4696-4702.

Subedi KP, Kim I, Kim J, Min B, et al. (2008). Role of GldA in dihydroxyacetone and methylglyoxal metabolism of Escherichia coli K12. FEMS Microbiol. Lett. 279: 180-187.

Tang CT, Ruch FE, Jr. and Lin CC (1979). Purification and properties of a nicotinamide adenine dinucleotide-linked dehydrogenase that serves an Escherichia coli mutant for glycerol catabolism. J. Bacteriol. 140: 182-187.

Thanassi DG, Cheng LW and Nikaido H (1997). Active efflux of bile salts by Escherichia coli. J. Bacteriol. 179: 2512-2518.

Torres AG, Tutt CB, Duval L, Popov V, et al. (2007). Bile salts induce expression of the afimbrial LDA adhesin of atypical enteropathogenic Escherichia coli. Cell Microbiol. 9: 1039-1049.

Truniger V and Boos W (1994). Mapping and cloning of gldA, the structural gene of the Escherichia coli glycerol dehydrogenase. J. Bacteriol. 176: 1796-1800.

Weber A, Kogl SA and Jung K (2006). Time-dependent proteome alterations under osmotic stress during aerobic and anaerobic growth in Escherichia coli.J. Bacteriol. 188: 7165-7175.

Westermeier R and Naven T (2002). Proteomics in Practice. A Laboratory Manual of Proteome Analysis. Weinheim: Wiley-VCH.

Wolfe AJ (2005). The acetate switch. Microbiol. Mol. Biol. Rev. 69: 12-50.

Wolfe AJ, Chang DE, Walker JD, Seitz-Partridge JE, et al. (2003). Evidence that acetyl phosphate functions as a global signal during biofilm development. Mol. Microbiol. 48: 977-988.

Xia XX, Han MJ, Lee SY and Yoo JS (2008). Comparison of the extracellular proteomes of Escherichia coli B and K-12 strains during high cell density cultivation. Proteomics 8: 2089-2103.

Xu H, Caimano MJ, Lin T, He M, et al. (2010). Role of acetyl-phosphate in activation of the Rrp2-RpoN-RpoS pathway in Borrelia burgdorferi. PLoS Pathog. 6: e1001104.

Zhang K, Zhao WD, Li Q, Fang WG, et al. (2009). Tentative identification of glycerol dehydrogenase as Escherichia coli $\mathrm{K} 1$ virulence factor cglD and its involvement in the pathogenesis of experimental neonatal meningitis. Med. Microbiol. Immunol. 198: 195-204. 